DOI: https://doi.org/10.24867/06AM01Oluski

\title{
ISTRAŽIVANJE STRUJANJA JONSKE TEČNOSTI PRIMENOM RAČUNARSKE DINAMIKE FLUIDA
}

\section{RESEARCH OF IONIC LIQUID FLOW USING COMPUTATIONAL FLUID DYNAMICS}

\author{
Nikola Oluški, Fakultet tehničkih nauka, Novi Sad
}

\section{Oblast - MAŠINSTVO}

Kratak sadržaj - Predmet rada jeste strujanje jonske tečnosti N-butil N,N,N trimetilamonijum bis(trihlormetilsulfonil)imid, skraćeno [N $\left.{ }_{4111}\right]\left[N T f_{2}\right]$, kroz pravu cev. Cilj rada jeste istraživanje prinudne konvekcije $i$ hidrauličkih karakteristika pri strujanju jonske tečnosti kroz pravu cevnu deonicu. Istraživanje je urađeno primenom računarske dinamike fluida pomoću programskog paketa StarCCM+. Pri analizi termičkih $i$ hidrauličkih karakteristika zaključeno je da predmetna jonska tečnost ne predstavlja najbolje rešenje kao medijum za prenos toplote za date uslove.

Ključne reči: Računarska dinamika fluida, jonska tečnost

Abstract - The subject of the paper is the flow of an ionic liquid $\quad \mathrm{N}$-butyl-N,N,N-trimetylammonium bis(trifluormethylsulfonyl)imide $\left[N_{4111}\right]\left[N T f_{2}\right]$ through a straight tube. The aim of this paper is to investigate forced convection and hydraulic characteristics in a straight pipe section. The research was performed using computational fluid dynamics, in the StarCCM+ software package. Analyzing the thermal and hydraulic characteristics, it was concluded that this ionic liquid does not represent the best solution as a medium for heat transfer for the given conditions.

Keywords: Computational fluid dynamics, ionic liquids

\section{UVOD}

Jonske tečnosti su mešavine suprotno naelektrisanih jona povezanih kovalentnom vezom, tačnije rastvarači koji se u potpunosti sastoje od jona. Kako je u hemiji so postala opšti izraz za jonska jedinjenja, onda se još može reći da su to soli koje se nalaze $u$ tečnom stanju na sobnoj temperaturi.

Jonske tečnosti, kao još uvek nedovoljno istraženi fluidi, mogu imati veliki uticaj u budućnosti kada je u pitanju prenos i akumulacija toplotne energije. Poseduju takve osobine da se mogu koristiti za prenos toplote od niskih (hemijska postrojenja, rashladni sistemi) do visokih temperatura (sakupljanje i skladištenje solarne energije).

Zbog navedenih karakteristika početkom 21. veka počinje detaljnije istraživanje ovih fluida, kao medijuma za sisteme toplotnog skladištenja i prenos toplote. 2000. g., grupa autora, ispituje termička svojstva nekoliko imidazolijumskih soli. Zapažaju da imaju niže tačke topljenja

\section{NAPOMENA:}

Ovaj rad proistekao je iz master rada čiji mentor je bio dr Siniša Bikić, vanr. prof. i termički su stabilnije od litijum jona, a termička stabilnost raste sa alkilnom supstitucijom [1]. Naučnici 2008. godine otkrivaju da toplotna provodljivost jonske tečnosti ima veoma malu zavisnost od molske frakcije $\mathrm{CO}_{2}$, kada je u pitanju jonska tečnosti na bazi imidazolijuma [2]. Grupa naučnika radila je eksperimentalno istraživanje termo-fizičkih osobina jonske tečnosti $\left[\mathrm{N}_{4111}\right]\left[\mathrm{NTf}_{2}\right]$, za njenu potencijalnu primenu $\mathrm{u}$ centralnim solarnim kolektorima [3]. Iako je koeficijent prenosa toplote niži nego kod destilovane vode, njena toplotna stabilnost $\mathrm{i}$ druga svojstva čine je kandidatom za korišćenje u solarnim elektranama.

Cilj rada jeste da se istraže prinudna konvekcija i hidrauličke karakteristike jonske tečnosti kroz pravu cevnu deonicu. Istraživanje prinudne konvekcije uradiće se analizom Nuseltovog broja $N u$ i koeficijenta prelaza toplote $\alpha$, dok će se istraživanje hidrauličkih karakteristika uraditi analizom pada pritiska $\Delta p$ i koeficijenta trenja $\lambda$.

\section{MATERIJAL I METOD}

\subsection{Uvod}

Primenom računarske dinamike fluida ponoviće se istraživanje strujanja i prenosa toplote jonske tečnosti koje je predhodno eksperimentalno urađeno. Fizička svojstva dobijena eksperimentalnim istraživanjem koristiće se za podešavanje numeričke simulacije.

\subsection{Eksperimentalno postrojenje}

$\mathrm{Za}$ eksperimentalno ispitivanje jonske tečnosti napravljeno je cirkulaciono postrojenje, čiji je deo šematski prikazan na slici 1 . Postrojenje čine rezervoar, pumpa, ispitna sekcija, toplotni izmenjivač, rezervoari za skladištenje tečnosti i trokraki ventil.

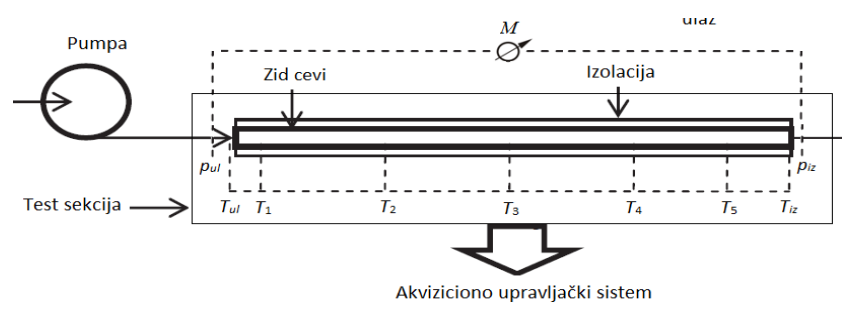

Slika 1 Test sekcija eksperimentalnog postrojenja [3]

\subsection{Verifikacija podataka}

Razmatrano je stacionarno, potpuno razvijeno, laminarno strujanje nestišljivog fluida kroz pravu cev. Za potvrdu tačnosti rezultata numeričke simulacije vrši se verifikacija poznatim podacima iz literatura i rezultatima prethodnih 
eksperimentalnih istraživanja. Eksperimentalni podaci dobijeni predhodnim istraživanjem [3] pokazuju da se jonska tečnost, kao i voda, ponaša kao Njutnovski fluid. Takođe jonska tečnost ima iste trednove promene fizičkih svojstava sa temperaturom kao i voda. Zbog toga je voda izabrana kao fluid za utvrđivanje tačnosti.

Korišćeni su izrazi za određivanje pada pritiska, Nuseltovog broja i koeficijenta trenja:

$$
\begin{gathered}
\Delta p=\lambda \frac{L}{D} \cdot \frac{\rho \cdot v^{2}}{2} \\
N u=\frac{\alpha \cdot D}{k_{f}} \\
\lambda=\frac{2 \cdot \Delta p \cdot D}{\rho \cdot L \cdot v^{2}}
\end{gathered}
$$

gde su: $\Delta p$ pad pritiska $[\mathrm{Pa}], L$ dužina cevi $[\mathrm{m}], D$ unutrašnji prečnik cevi $[\mathrm{m}], \rho$ gustina fluida $\left[\mathrm{kg} / \mathrm{m}^{3}\right], v$ brzina strujanja tečnosti $[\mathrm{m} / \mathrm{s}], \lambda$ koeficijent trenja [-], $\alpha$ koeficijent prelaza toplote $\mathrm{i} k_{f}$ toplotna provodljivost [W/mK.]

Relativna greška $\varepsilon$ za ocenu odstupanja stvarne od izmerene vrednosti glasi.

$$
\varepsilon=\frac{\Delta p_{\text {sim }}-\Delta p_{D-W}}{\Delta p_{D-W}} \cdot 100
$$

gde su: $\varepsilon$ relativna greška [\%], $\Delta p_{\text {sim }}$ pad pritiska određen pomoću numeričke simulacije $[\mathrm{Pa}]$ i $\Delta p_{D-W}$ pad pritiska određen pomoću Darsi-Vajsbahove formule [Pa].

Pored klasične formule za određivanje $N u$ koriste se i empirijske kriterijalne jednačine poput Šahove jednačine:

$$
N u(x)= \begin{cases}1,953\left(\operatorname{RePr} \frac{D}{x}\right)^{\frac{1}{3}} & \left(\operatorname{RePr} \frac{D}{x}\right) \geq 33,3 \\ 4,364+0,0722 \operatorname{RePr} \frac{D}{x} & \left(\operatorname{RePr} \frac{D}{x}\right) \leq 33,3\end{cases}
$$

gde su: $x$ aksijalno rastojanje od ulaza cevi [m], Pr Prantlov broj [-] i Rejnoldsov broj Re [-].

Kao parametar za evaluaciju performansi prenosa toplote koristi se Mourcefov broj Mo [-]:

$$
\frac{M o_{n f}}{M o_{b f}}=\frac{k_{n f}}{k_{b f}}
$$

gde su $k_{n f}$ i $k_{b f}$ toplotne provodljivosti nanofluida i bazne tečnosti $[\mathrm{W} / \mathrm{mK}]$. U slučaju potpuno razvijenog laminarnog strujanja Mourcefov $M o$ za nanofluid u odnosu na vodu jednak je odnosu odgovarajućih toplotnih provodljivosti

\subsection{Podešavanje numeričke simulacije}

Za pravljenje geometrijskog modela koristiće se grafički editor programskog paketa StarCCM+ pod nazivom
3D-CAD. Kako bi se simulacija odvijala što brže, uzdužno je iz cevi izdvojen klin od $15^{\circ}$, slika 2. Na ovaj način znatno će se smanjiti broj ćelija i ubrzati izvršenje numeričke simulacije. Treba napomenuti da su numeričke simulacije podešene uz određene aproksimacije:

- jonska tečnost je posmatrana kao jednofazni fluid;

- fizička svojstva jonske tečnosti podešena su za konstantnu vrednost temperature koja odgovara temperaturi tečnosti na ulazu u region i

- toplotni fluks se dovodi na unutrašnji zid cevi i usvojena je vrednost toplotnog fluksa iz kataloga proizvođača;

Na ulazu u region podesiće se brzina i temperatura jonske tečnosti, na zidu će se zadati konstantna vrednost toplotnog fluksa od $13300 \mathrm{~W} / \mathrm{m}^{2}$, dok će se na izlazu izabrati opcija Field Function. Na zidu je podešen uslov No-Slip što znači da fluid na čvrstoj granici ima nultu brzinu u odnosu na tu granicu, odnosno nema klizanja između tečnosti i zida. Generisani broj ćelija mrežnog kontinuma iznosio oko 143000.

Dva osnovna kriterijuma konvergencije su korišćena za zaustavljanje iterativnog postupka kada rezultat postane dovoljno tačan:

- relativni ostaci pri rešavanju jednačina $\left(<10^{-4}\right) \mathrm{i}$

- vrednost pada pritiska kao fizičke veličine od interesa između dve poslednje iteracije $(<1 \%)$.

Prilikom simulacije, veća važnost je data drugom kriterijumu konvergencije, tj. fizičkoj veličini od interesa, a to je bio pad pritiska.

\section{REZULTATI I DISKUSIJA}

Pre iznošenja rezulatata dobijenih za jonsku tečnost prikazaće se rezultati verifikacije numeričkog modela.

\subsection{Verifikacija rezulata}

Pad pritiska tokom nerazvijenog strujanja je veći od pada pritistka na istoj dužini cevi sa razvijenim strujanjem. Ovo je posledica konverzije energije pritiska u kinetičku energiju i većeg trenja. Izvršavanjem numeričke simulacije dobija se pad pritiska od $\Delta p_{\text {sim }}=433,6 \mathrm{~Pa}$. Korišćenjem formule (1) dobija se vrednost pada pritiska od $\Delta p_{D-W}=430,4 \mathrm{~Pa}$.

Izračunavanjem relativne razlike između simulacije $\mathrm{i}$ formule (1) dobija se vrednost $\varepsilon=0,7 \%$ što se može smatrati prihvatljivim odstupanjem izmerene od stvarne vrednosti.

Ovim je potvrđen numerički model koji će se koristiti za numeričke simulacije jonske tečnosti $\left[\mathrm{N}_{411}\right]\left[\mathrm{NTf}_{2}\right]$.

\subsection{Pad pritiska}

Jonska tečnost na sobnoj temperaturi je i dalje tečljiva. Međutim, gustina i dinamička viskoznost imaju znatno

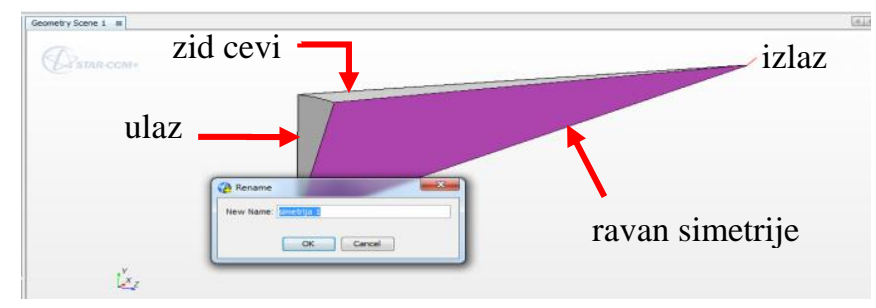

Slika 2. Izgled geometrijskog modela 
veću vrednost od vode, što otežava transport ovih fluida kroz cevi malog prečnika. Iz tog razloga razmatrane su veće temperature za istraživanje fizičkih osobina predmetne jonske tečnosti, slika 3.

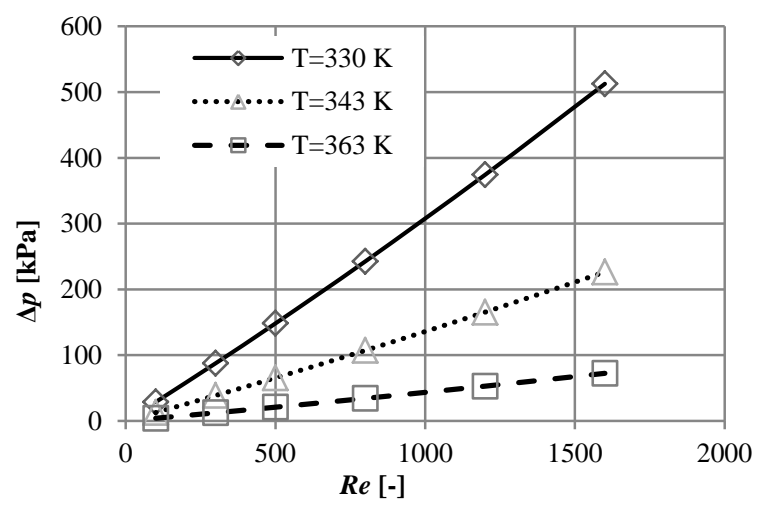

Slika 3 Zavisnost pada pritiska od Rejnoldsovog broja za tri različite temperature jonske tečnosti na ulazu u cev

Moguće je primetiti da sa porastom temperature dolazi do značajnog smanjenja vrednosti pada pritiska. Uzrok toga je značajno smanjenje dinamičke viskoznosti sa povećanjem temperature jonske tečnosti. Međutim, ove vrednosti su i dalje daleko veće nego kod vode, što ne predstavlja povoljnu karakteristiku.

\subsection{Nuseltov broj}

Na slici 4 prikazana su rešenja numeričke simulacije pri istim $R e$ kao u eksperimentu. Trebalo bi napomenuti da autor eksperimenta nije definisao tačnu temperaturu pri kojoj je vršio merenja, već samo opseg, pa su zbog toga ali i ostalih aproksimacija u odnosu na fizički model moguća mala odstupanja u rezultatima.

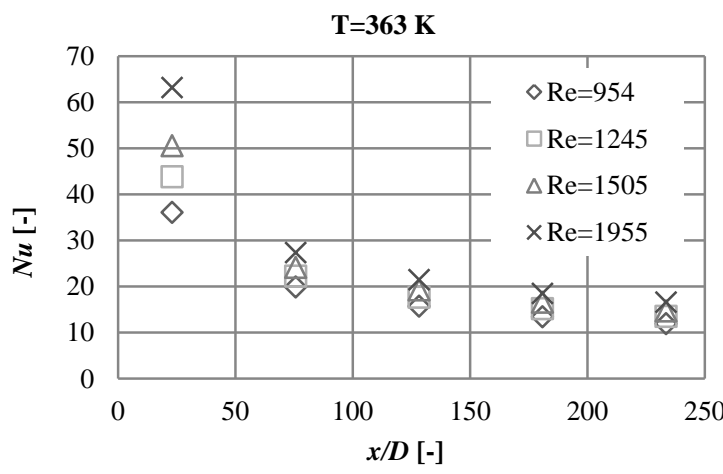

Slika 4 Zavisnost Nuseltovog broja $\mathrm{Nu}$ od bezdimenzionog rastojanja za razlicite vrednosti Rejnoldsovog broja

Ukoliko je laminarno strujanje sa konstantnim toplotnim fluksom i ukoliko je potpuno razvijeno strujanje, Nuseltov broj će biti konstantan i iznosiće 4,36 i neće zavisiti od $\operatorname{Re}$ i $\operatorname{Pr}$ [4]. Sa slike 4 vidi se da Nuseltov broj opada sa povećanjem aksijalne udaljenosti. Razlog naglog pada je ulazni efekat, tačnije nerazvijeni termički sloj. Na samom ulazu dominira konvekcija, jer se toplota predaje sa zida cevi direktno u tečnost.

Iz razloga što nije dobijeno poklapanje vrednosti Nuseltovih brojeva $\mathrm{Nu}$ na istom aksijalnom rastojanju može se sa sigurnošću potvrditi da termički granični sloj nije potpuno razvijen.

\subsection{Koeficijent prelaza toplote}

Koeficijent prelaza toplote najčešće zavisi od brzine strujanja, gustine, dinamičke viskoznosti tečnosti, kao i geometrije cevi. Kako se geometrija nije menjala, primećuje se da koeficijent prelaza toplote opada sa povećanjem temperature što je uobičajeno za većinu tečnosti, slika 5 .

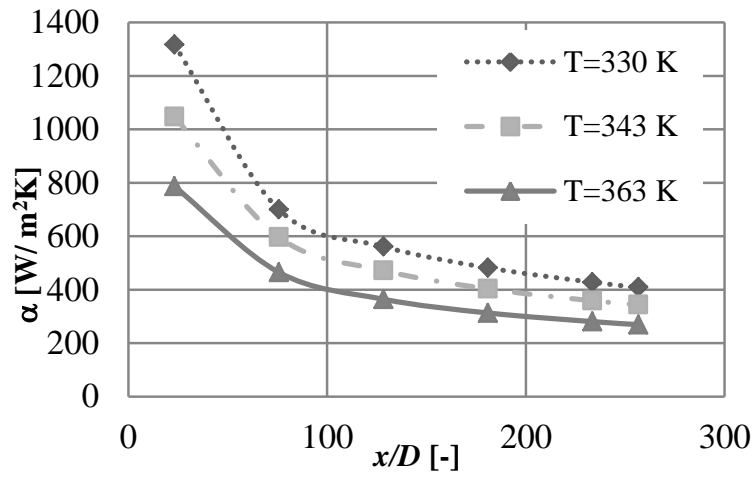

Slika 5 Zavisnost koeficijenta prelaza toplote od bezdimenzionog rastojanja za različite temperature jonske tečnosti na ulazu u cev

Do pada dolazi iz razloga što se temperatura fluida približava temperaturi zida tokom strujanja. Kako je razlika između temperatura sve manja i koeficijent prelaza toplote postaje manji.

\subsection{Koeficijent trenja}

Koeficijent trenja je određen primenom računarske dinamike fluida $i$ jednačine (3) na tri različite temperature, uz variranje Rejnoldsovog broja, slika 6. Na dijagramu se primećuje kako $\lambda$ opada sa povećanjem $R e$, što predstavlja povoljnu karakteristiku ove jonske tečnosti. Pri manjim vrednostima Rejnoldsovog broja $R e$ dešava se značajnija promena, dok sa povećanjem Rejnoldsovog broja $R e$ koeficijent trenja počinje da se ustaljuje.

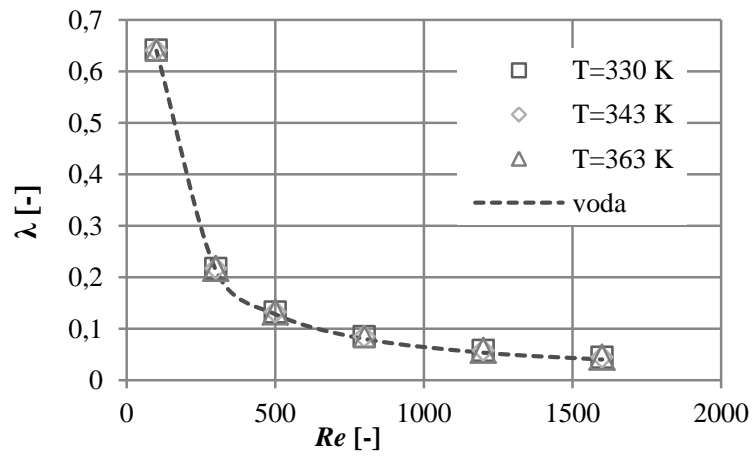

Slika 6 Zavisnost koeficijenta trenja od Rejnoldsovog broja Re za različite vrednosti temperature na ulazu u cev Na slici 6 vidi se kako koeficijent trenja ima istu vrednost za sve tri razmatrane temperature jonske tečnosti. Radi se o svojevrsnoj verifikaciji rezultata numeričke simulacije, jer za laminarno strujanje Njutnovskog fluida koeficijent trenja mora da se povinuje Stoksovoj jednačini.

\subsection{Mourcefov broj}

Za kraj je ostavljeno da se uradi sveukupna procena jonske tečnosti, kako bi se ustanovilo da li je njena 
primena smislena u procesima prenosa toplote. Procena je izvršena preko Mourcefovog broja, tačnije poređenjem toplotne provodljivosti jonske tečnosti i toplotne provodljivosti vode, slika 7.

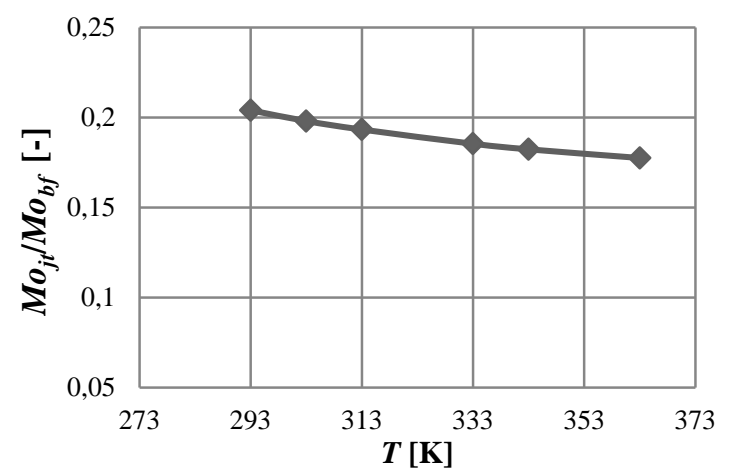

Slika 7 Zavisnost odnosa Mourcefovih brojeva jonske tečnosti $i$ vode od temperature

Sa slike se primećuje da odnos Mourcefovih brojeva jonske tečnosti i vode, formula (6), kontinualno opada sa povećanjem temperature. Kako je dobijena vrednost znatno manja od 1, a opšte prihvaćen uslov kaže da su samo vrednosti veće od 1 vredne razmatranja [5], zaključuje se da ova tečnost i nije baš najbolje rešenje kada je u pitanju primena kod solarnih kolektora. Treba napomenuti da je određivanje ovog broja uslovno iz razloga što se on primenjuje za procenu nano fluida.

\section{ZAKLJUČAK}

Predmet master rada bilo je strujanje jonske tečnosti kroz pravu cev, kružnog poprečnog preseka unutrašnjeg prečnika $D=3,86 \mathrm{~mm}$ i dužine $L=990,6 \mathrm{~mm}$, pri laminarnom režimu i stacionarnim uslovima strujanja.

Cilj rada bio je da se istraži prinudna konvekcije i hidrauličke karakteristike pri strujanju jonske tečnosti kroz pravu cevnu deonicu. Analizom Nuseltovog broja $N u$, koeficijenta prelaza toplote $\alpha$, pada pritiska $\Delta p$, koeficijenta trenja $\lambda$ i Mourcefovog broja Mo dobijena je jasnija slika o prinudnoj konvekciji i strujanju jonske tečnosti kroz pravu cev.

Istraživanje je urađeno primenom računarske dinamike fluida, pomoću programskog paketa StarCCM+. Mreža je većim delom struktuirana sačinjena od tetraedarskih i heksaedarskih ćelija, sa ukupnim brojem ćelija fizičkog modela od oko 143000. Kao kriterijum zaustavljanja podešen je maksimalan broj iteracija, a praćene su dve relevantne fizičke veličine od interesa: relativni ostaci pri rešavanju sistema jednačina i vrednost pada pritiska. Pad pritiska je veličina koja je služila za verifikaciju rezultata numeričke simulacije.

Pri analizi podataka uočeno je da pad pritiska znatno opada sa porastom temperature. Ova pojava može se pripisati velikoj zavisnosti viskoznosti od temperature, kao kod većine tečnosti. U poređenju sa rezultatima simulacije dobijenim za vodu može se primetiti da pad pritiska kod jonske tečnosti ima i do 1.000 puta veću vrednost pri istim vrednostima Rejnoldsovih brojeva $R e$ zbog velike vrednosti dinamičke viskoznosti. Usled toga predlaže se da se u daljem istraživanju ovako visoka vrednost pada pritiska predmetne jonske tečnosti potvrdi eksperimentalnim putem.
Nuseltov broj $\mathrm{Nu}$ uglavnom varira u granicama od 1 do 10. U poređenju sa vodom, jonska tečnost ima veće vrednosti Nuseltovog broja. Ovo ukazuje da je konvekcija izraženija kod jonske tečnosti nego kod vode. Razvijanjem profila brzine (povećanjem aksijalnog rastojanja) Nuseltov broj $\mathrm{Nu}$ približava se vrednosti od 4,36, koja važi za potpuno razvijeni termički granični sloj pri konstantnom toplotnom fluksu.

Kod koeficijenta prelaza toplote sasvim očekivano dobija se ista tendencija kao i kod Nuseltovog broja. Sa porastom temperature i udaljavanjem od ulaza cevi koeficijent prelaza toplote kontinualno opada, a vrednosti su pribležne vrednostima za vodu.

$\mathrm{Na}$ kraju je urađeno izračunavanje Mourcefovog broja $M o$, procenitelja da li je upotreba ove tečnosti interesantna kao medijum za prenosa toplote. Kao granična vrednost određen je broj 1. Ukoliko je dobijena vrednost manja od granične smatra se da nije smisleno korišćenje, što je slučaj kod predmetne jonske tečnosti. Treba napomenuti da je određivanje ovog broja uslovno iz razloga što se on primenjuje za procenu nano fluida.

\section{LITERATURA}

[1] McEwen A.B., Ngo H.L., LeCompte K., Hargens L., (2000). Thermal properties of imidazolium ionic liquids, Thermochimica Acta, 357-358 (2000), 97-102.

[2] Tomida D., Kenmochi S., Tsukada T., Qiao K., Yokoyama C., (2010). Thermal Conductivities of Imidazolium-Based Ionic Liquid $+\mathrm{CO}_{2}$ Mixtures, Int J Thermophys 31 (10), 1888-1895.

[3] Paul T.C., Morshed A.K.M.M., Fox E.B., Visser A.E., Bridges N.J., Khan J.A., (2014). Thermal performance of ionic liquids for solar thermal applications, Experimental Thermal and Fluid Science 59 (2014), 88-95.

[4] Incropera F., DeWitt D., Bergman T., Lavine A., Fundamentals of Heat and Mass Transfer, sixth edition, John Wiley \& Sons, Inc (2007).

[5] Zyla G., Fal J., (2017). Viscosity, thermal and electrical conductivity of silicon dioxide-ethylene glycol transparent nanofluids: An experimental studies, Thermochimica Acta 650 (2017), 106-113.

\section{Kratka biografija:}

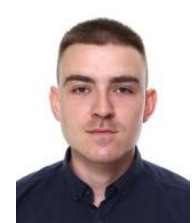

Nikola Oluški rođen je u Novom Sadu 1994. god. Master rad na Fakultetu tehničkih nauka iz oblasti Mašinstva - Energetika i procesna tehnika odbranio je 2019.god. kontakt: oluski.nikola@gmail.com 